\title{
errata
}

\section{An atomic model of fimbrin binding to F-actin and its implications for filament crosslinking and regulation}

Dorit Hanein, Niels Volkmann, Sharon Goldsmith, Anne-M arie Michon, William Lehman, Roger Craig, David DeRosier, Steve Almo and Paul Matsudaira Nature Struct. Biol. 5, 787-792 (1998).

Due to a printer's error, Fig. $4 c$ was misprinted. The correct version is shown below.

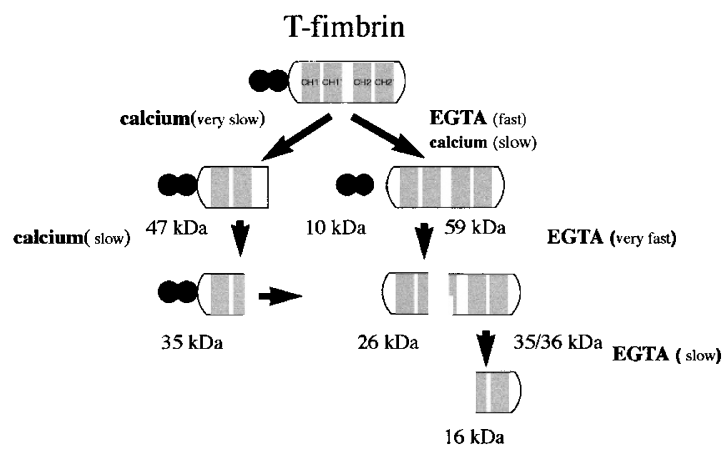

\section{correction}

\section{Structure of the ATP-dependent oligomerization domain of $\mathrm{N}$-ethylmaleimide sensitive factor complexed with ATP}

Richard C. Yu, Phyllis I. Hanson, Reinhard Jahn and Axel T. Brünger Nature Struct. Biol. 5, 803-811 (1998).

In this paper, Fig. $4 c$ was mistakenly printed upside down.

\section{A protein disulfide oxidoreductase from the archaeon Pyrococcus furiosus contains two thioredoxin fold units}

Bin Ren, Gudrun Tibbelin, Donatella de Pascale, Mosè Rossi, Simonetta Bartolucci and Rudolf Ladenstein Nature Struct. Biol. 5, 602-611 (1998).

The authors would like to note that the structural figures were generated using the programs Molscript ${ }^{1}, \mathrm{Setor}^{2}, \mathrm{O}^{3}$ and Grasp ${ }^{4}$. Sequence alignments were produced using Alscript ${ }^{5}$.

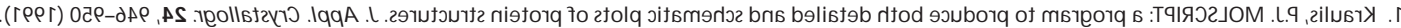

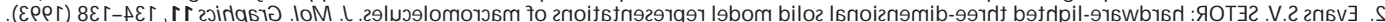

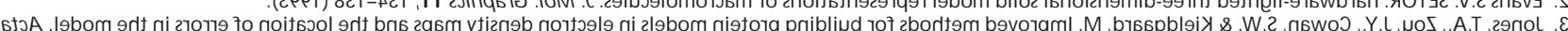

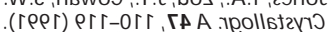

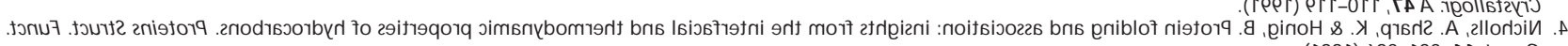

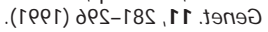

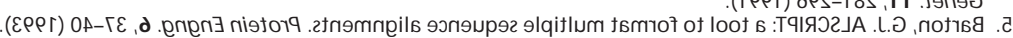

